\title{
Risk perception and behavioral response to COVID- 19 in Iraqi Kurdistan Region
}

Sherzad Shabu ( $\nabla$ sherzad.hakim@hmu.edu.krd)

Hawler Medical University https://orcid.org/0000-0001-8887-106X

\section{Karwan M Amen}

Hawler Medical University

\section{Kazhan I. Mahmood}

Hawler Medical University

\section{Nazar P. Shabila}

Hawler Medical University

\section{Research article}

Keywords: COVID-19, novel corona virus, risk perception, behavioral response, Iraq, Kurdistan Region

Posted Date: April 12th, 2020

DOl: https://doi.org/10.21203/rs.3.rs-22025/v1

License: @ (i) This work is licensed under a Creative Commons Attribution 4.0 International License. Read Full License 


\section{Abstract}

\section{Background}

Understanding how people perceive the risk of the coronavirus disease (COVID-19) outbreak and its impact on undertaking protective behavior can guide the public health policymakers in taking the required measures to limit the magnitude of this outbreak. This study aimed to understand the risk perception and the behavioral response of the university academics and students towards the COVID-19.

\section{Methods}

A self-administered online survey was conducted among the academic staff and university students in Iraqi Kurdistan Region. The survey questionnaire included eight main questions about the main aspects of personal risk perception and behavioral response to COVID-19 based on a five or nine-point ordinal scale. The eight questions included the number of contacts, the perceived threat level of COVID-19, personal risk perception, ability to avoid infection, frequency of undertaking the protective measures, adherence to the curfew, the negative impact of COVID-19 on life, and sources of obtaining information.

Results

A total of 976 individuals participated in the study with a mean age \pm SD of $25.8 \pm 9.7$ years. The respondents had the highest perceived threat level towards COVID-19 (mean score $=2.79$ ) in comparison to other medical threats. Around $62 \%$ of respondents had no contacts outside their homes. A high percentage of the respondents perceived their risk of getting infection, serious illness, and death as highly unlikely $(26.9 \%, 29.7 \%$, and $41.7 \%$, respectively). The percentage of the respondents who applied these measures frequently or always was high for most of the behaviors, except for wearing masks, wearing gloves, and avoiding touching face. There was a significant $(P<0.001)$ weak positive correlation between risk perception with protective behaviors; overall risk ( $b e t a=0.080, r=0.189$ ), risk of getting infection (beta $=0.066, r=0.179)$, risk of getting serious illness (beta $=0.070, r=0.176)$ and risk of death (beta $=0.058$, $r=0.154)$.

\section{Conclusion}

The perceived risk of getting infection with COVID-19 is relatively low. The respondents follow protective behavior measures reasonably. However, the frequency of undertaking some important protective behaviors is relatively low. The risk perception of COVID-19 has a weakly positive impact on following protective behavior. Changing behavior remains a challenge even for the well educated and well aware people.

\section{Background}

The novel coronavirus disease (COVID-19) is caused by a newly discovered coronavirus. The mode of transmission of COVID-19 is mainly from person-to-person by respiratory transmission and from contact 
with contaminated surfaces. It is expected that people infected with this virus will mainly experience mild to moderate respiratory illness before they recover without the need for a specific treatment. People who are at the risk of developing some sorts of serious signs and symptoms could be older people and those who already have other medical problems like diabetes, chronic cardiac and respiratory diseases, and those with cancer [1].

Recently, it was announced that COVID-19 entered a pandemic status. In addition to China, Iran, Italy, and South Korea, which experienced a massive spread of the disease, many other countries have developed small chains of the transmission, and many other countries are expected to experience the spread of COVID-19, even though in the early stages [2].

Since no specific vaccines or treatments have been developed or confirmed for this virus, avoiding the exposure is considered the best available way to prevent the infection with this virus. On a personal level, this can be achieved through following some basic protective measures. The most important protective measures include frequent handwashing, maintaining distance with anyone who is sneezing or coughing, avoiding touching nose, mouth, and eyes, and covering mouth and nose while coughing and sneezing. Other protective measures include staying at home whenever feeling unwell and seeking medical advice when developing a fever, cough, and breathing difficulty [3].

Human perception and behavioral responses to the risk of the epidemic has always been a crucial factor to study during the spread of the disease. How the risk of the disease is assessed by the people, and in what ways such assessment affects the change in people's behavior as keeping the distance from other people can minimize the spread of the disease [4]. In general, and in many epidemics, information on people's perceptions and their behavioral response are not usually collected at the beginning of an epidemic. There has always been some delay in data collection for this purpose as it was the case with influenza A (H1N1) [5], following the end course of the epidemic as it was the case with SARS [6], or before the stage of establishing a human to human transmission as it was the case with avian influenza A (H5N1) [7]. The chance for limiting the spread of any epidemics or infectious disease is much higher during the early stages of an infectious disease. Therefore, providing useful information for public health policymakers can be achieved through data collection on people's perception and behavioral response to this epidemic as early as in the first stages of an epidemic [8].

Iraq, in general, and the Kurdistan Region were also affected by the rapidly evolving situation of COVID19. Measures of continuous observation were put in place by the Ministry of Health of the Kurdistan Regional Government (KRG) to handle and deal with any cases when they occur, and health facilities to contain these cases were also settled and equipped accordingly. Different measures were taken by the KRG to mitigate the spread of the disease, including cross-border movement limitation with health screening at all the points of entry, banning flights from all Kurdistan Region's airports, suspension of all types of public transportation, and closing all tourist centers. This was followed by more strict measures, including closing all public and private schools and universities and suspending the work in all 
government offices, and quarantining everyone reported being in contact with the infected people for a duration of time set by the Ministry of Health. Finally, a curfew was imposed in all governorates [9].

Knowing how people perceive this outbreak and their behavioral response toward it can guide the public health policymakers in taking the required measures to limit the spread of this outbreak. This study aimed to assess and understand the risk perception and the behavioral response of the university academics and students towards the novel coronavirus disease.

\section{Methods}

\section{Design and setting}

A self-administered online survey designed on Google form was carried out in Erbil, Iraqi Kurdistan Region, from 20 to 26 March 2020. The survey was carried out during schools and universities closure and curfew period. The schools and universities in Iraqi Kurdistan Region were closed on 26 and 29 February 2020, respectively. The governmental offices were closed on 11 March 2020, and the curfew started on 13 March 2020. When the survey started, i.e., on 20 March 202, 47 cases of COVID-19 were detected in Iraqi Kurdistan Region, including one death. By 26 March 2020 when the survey was closed, 103 cases and two deaths were recorded in the region. By 4 April 2020, 214 cases, three deaths, and 74 recoveries were recorded.

\section{Study participants and data collection}

All teaching staff and students of the public and private universities in Iraqi Kurdistan Region were invited to participate in this survey. The URL link for the survey material was (https://forms.gle/btwAF71uzk5zvjFGA). In addition to the official university's e-mail addresses, social networking sites like Viber, WhatsApp, and Twitter were also used to share the survey link with students and teaching staff. The invitation message and the introduction part of the online survey explained the purpose of the survey to the participants, requested a consent to participate, and explained the anonymity of the participants and confidentiality of the collected information.

\section{Survey tool}

The survey's questionnaire was designed to get a rapid appraisal of the risk perception and behavioral response of Hawler Medical University students and the teaching staff of COVID-19. The questionnaire was developed based on reviewing the literature of similar outbreaks related to other infections in the past $[8,10,11]$ and on experts' opinions. The first part of the questionnaire included information about some socio-demographic criteria of the participants, such as age, gender, college, and home address. The second part included eight main sections where questions were asked mainly based on a five or ninepoint ordinal scale, highlighting very high, intermediate, and very low points of the scale.

The first section was about the number of contacts outside the house during the last 24 hours, which ranged from zero to $>100$ on seven ordered categories. The second section was about the perceived 
threat level of COVID-19 in comparison with other leading health threats like diabetes, heart diseases, cancer, unintentional injuries, influenza, which was based on a five-point scale. The third section was about personal risk perception of COVID-19 in terms of the risk of getting an infection, the risk of getting a severe illness, and the risk of dying, which was based on a nine-point scale. The fourth section was bout the ability to avoid infection with COVID-19, which was based on a nine-point scale. The fifth section was about the frequency of undertaking the main protective measures against COVID-19 like avoiding sneezing/couching, avoiding touching face, nose, and eyes, avoiding large gatherings and public places, avoiding traveling to the affected areas, staying at home, using alcohol-based disinfectants, and wearing mask/gloves. This section was based on a 5 point scale from 1 none to 5 always. The sixth section was about adherence to the current curfew regulations, which was based on a five-point scale from none to completely. The seventh section was about the negative impact of COVID-19 on their life like daily activity routine and sleeping, which was based on a five-point scale from no impact to extreme impact. The last section was about the sources of obtaining information about COVID-19 like different media channels, social media, family and friends, health staff, which was based on a five-point scale from never to very frequently. The survey link was initially sent to a number of teaching staff to test the clarity of the content/questions and the practicality of completing and submitting the online questionnaire.

\section{Data analysis}

Data were analyzed using the Statistical Package for the Social Sciences (SPSS), Version 22.0 (IBM Corp., Chicago, Illinois, USA). The descriptive statistical analysis involved summing the scores for all items in each component to determine mean scores and $95 \%$ confidence interval. The effect of risk perception on behavioral response was examined using linear regression and correlation coefficient. Four models of risk perception were used that included risk of getting infection, risk of getting a serious illness, risk of death and overall risk. For the overall risk, we used the mean score of the previous three risks. Two models of behavioral response. In the first model, the mean score of all protective behaviors together was used. In the second model, we used the mean score of the four main protective behaviors recommended by the WHO, including handwashing, social distancing, respiratory hygiene, and avoid touching the face, mouth, nose, and eyes.

\section{Ethical considerations}

This study was approved by the Research Ethics Committee of Hawler Medical University. Participants' consent was obtained before completing the survey. All participants were informed about the voluntary nature of participation and the anonymity and confidentiality of information.

\section{Results}

Table 1 shows the demographic data of the study sample. The total number of respondents was 976 individuals (teaching faculties and students). The mean age \pm SD of the sample was $25.8 \pm 9.7$ years old, and it ranged from 17 to 68 years old. Regarding the gender of the respondents, more than half of the sample (58.0\%) were females, and $42 \%$ were males. Concerning the role of the study respondents, most 
of them (72.2\%) were students, and only $27.8 \%$ were teaching staff. The highest percentage $(80 \%)$ of respondents originated from Erbil governorate, followed by Duhok (12.3\%), then Sulaiymaniyah (10.8\%).

Table 1

Demographic information of the respondents

\begin{tabular}{|lll|}
\hline Characteristic & No. & $\%$ \\
\hline Gender & & \\
Male & 410 & 42.0 \\
\hline Female & 566 & 58.0 \\
Role & & \\
\hline Student & 705 & 72.2 \\
\hline Teacher & 271 & 27.8 \\
\hline Governorate & & \\
\hline Erbil & 751 & 76.9 \\
\hline Sulaymaniyah & 105 & 10.8 \\
\hline Duhok & 120 & 12.3 \\
\hline Total & 976 & 100 \\
\hline
\end{tabular}

Figure 1 presents the mean score of the perceived threat level of COVID-19 compared to other important diseases. The respondents in the current survey had the highest perceived threat level towards COVID-19 as their mean score was 2.79 , and they had the lowest perceived threat level towards influenza as their mean score was 2.29. However, the next highest perceived threat score of respondents was cancer (2.63) followed by heart disease (2.53), unintentional injuries (2.43), and lastly, diabetes (2.32).

Regarding the number of contacts the respondents had outside their home during the last 24 hours, Table 2 shows that $61.7 \%$ of respondents had no contacts outside their home. However, more than a quarter $(28.3 \%)$ of respondents had one to five contacts outside their home, followed by $5.6 \%$ having contacts with six to ten individuals outside their households. 
Table 2

Number of contacts outside the home during the last 24 hours

\begin{tabular}{|lll|}
\hline Number of contacts & Frequency & Percent \\
\hline 0 & 602 & 61.7 \\
\hline $1-5$ & 276 & 28.3 \\
\hline $6-10$ & 55 & 5.6 \\
\hline $11-20$ & 27 & 2.8 \\
\hline $21-50$ & 7 & 0.7 \\
\hline $51-100$ & 3 & 0.3 \\
\hline$>100$ & 6 & 0.6 \\
\hline Total & 976 & 100.0 \\
\hline
\end{tabular}

A high percentage of the respondents perceived their risk of getting infection, serious illness, and death as highly unlikely $(26.9 \%, 29.7 \%$, and $41.7 \%$, respectively), as shown in Fig. 2 . Only $6.9 \%$ of respondents perceived their risk of getting infection highly likely, and $4 \%$ and $5.7 \%$ of respondents perceived their risk of getting severe illness and risk of death as highly likely, respectively.

Figure 3 illustrates the respondents' ability to avoid infection with the novel coronavirus (COVID-19). The highest percentage (17.3\%) of respondents perceived that their ability to avoid infection was intermediate, followed by $15.3 \%$ of respondents perceiving their ability to avoid infection as very high. The lowest percentage $(6.3 \%)$ of respondents perceived their ability to avoid infection as very low.

Table 3 shows the frequency of applying protective measures by the respondents against COVID-19, which is based on a five-point scale from none (0) to always (5). The percentage of the respondents who applied these measures frequently or always was high for most of the behaviors, except for wearing masks, wearing gloves, avoid touching face, and applying the measures before the curfew. The lowest mean score of respondents was using masks (3.11) and using gloves $(3,22)$. The highest mean scores were avoiding travel to affected areas (4.45). The mean score of undertaking the most important protective behavior was 4.19 for frequent handwashing, 4.14 for social distancing, 3.84 for respiratory hygiene, and 3.25 for avoiding touching face, mouth, nose, and eyes. The mean score of respondents' overall application of protective measures before the curfew was 3.41 , and adherence to the curfew regulation was 3.97. 
Table 3

The frequency of undertaking different protection measures by the participants

$\begin{array}{lll}\begin{array}{l}\text { Protection } \\ \text { behavior }\end{array} & \text { Frequency of undertaking protection measures in \% } & \begin{array}{l}\text { Mean score and 95\% } \\ \mathrm{Cl}\end{array}\end{array}$

\begin{tabular}{|c|c|c|c|c|c|c|c|c|}
\hline & None & Rarely & Sometimes & Frequently & Always & Mean & $95 \% \mathrm{C}$ & \\
\hline $\begin{array}{l}\text { Avoid people } \\
\text { sneezing or } \\
\text { coughing }\end{array}$ & 5.2 & 4.7 & 18.2 & 23.2 & 48.7 & 4.05 & 3.98 & 4.12 \\
\hline $\begin{array}{l}\text { Avoid large } \\
\text { gathering }\end{array}$ & 4.5 & 6.3 & 14.2 & 20.3 & 54.7 & 4.14 & 4.07 & 4.22 \\
\hline $\begin{array}{l}\text { Avoid touching } \\
\text { face, mouth, nose } \\
\text { and eyes }\end{array}$ & 10.0 & 15.8 & 32.3 & 23.2 & 18.8 & 3.25 & 3.17 & 3.32 \\
\hline $\begin{array}{l}\text { Wash hands } \\
\text { frequently }\end{array}$ & 3.8 & 5.2 & 12.7 & 24.8 & 53.5 & 4.19 & 4.12 & 4.26 \\
\hline $\begin{array}{l}\text { Avoid sick and } \\
\text { infectious people }\end{array}$ & 4.9 & 5.5 & 15.2 & 24.1 & 50.3 & 4.09 & 4.02 & 4.16 \\
\hline $\begin{array}{l}\text { Avoid public } \\
\text { places/public } \\
\text { transportation }\end{array}$ & 4.6 & 4.5 & 11.1 & 19.0 & 60.9 & 4.27 & 4.20 & 4.34 \\
\hline $\begin{array}{l}\text { Stay home from } \\
\text { school/work }\end{array}$ & 4.4 & 4.3 & 9.0 & 13.6 & 68.6 & 4.38 & 4.31 & 4.45 \\
\hline $\begin{array}{l}\text { Avoid travel to } \\
\text { affected areas }\end{array}$ & 5.0 & 3.6 & 7.4 & 8.9 & 75.1 & 4.45 & 4.39 & 4.52 \\
\hline $\begin{array}{l}\text { Used alcohol } \\
\text { based disinfectant }\end{array}$ & 15.2 & 10.0 & 20.1 & 20.6 & 34.1 & 3.48 & 3.40 & 3.57 \\
\hline $\begin{array}{l}\text { Using tissue when } \\
\text { sneezing or } \\
\text { coughing }\end{array}$ & 7.1 & 7.0 & 20.6 & 25.4 & 40.0 & 3.84 & 3.77 & 3.92 \\
\hline $\begin{array}{l}\text { Avoid spitting on } \\
\text { the ground }\end{array}$ & 6.4 & 5.5 & 14.5 & 15.6 & 58.0 & 4.13 & 4.06 & 4.21 \\
\hline Wearing a mask & 19.0 & 13.6 & 27.4 & 17.8 & 22.2 & 3.11 & 3.02 & 3.19 \\
\hline Wearing gloves & 18.6 & 12.6 & 24.4 & 16.7 & 27.7 & 3.22 & 3.13 & 3.31 \\
\hline $\begin{array}{l}\text { Take protective } \\
\text { measures before } \\
\text { the curfew }\end{array}$ & 7.8 & 12.4 & 29.4 & 31.5 & 19.0 & 3.41 & 3.34 & 3.49 \\
\hline $\begin{array}{l}\text { Adherence to the } \\
\text { curfew regulations }\end{array}$ & 5.7 & 9.2 & 16.0 & 20.9 & 48.2 & 3.97 & 3.89 & 4.04 \\
\hline
\end{tabular}


Regarding the impact of COVID-19 on sleeping, $62.7 \%$ of respondents stated that this outbreak had mild to extreme impact on them, including $13.3 \%$ who stated that it had an extreme impact on their sleeping. Around $87 \%$ of respondents graded that COVID-19 had a negative impact on their daily living routines, including $28 \%$ who considered it an extreme impact (Fig. 4).

Figure 5 illustrates the mean score of respondents obtaining information concerning COVID-19 from different sources. As stated earlier, this section was based on a five-point scale from never $(0)$ to very frequently (5). Respondents used the website as the most frequently used source of information as it had the maximum mean score (3.91). The second most commonly used source of information was social media, with a mean score of 3.71. Watching TV (3.33) was the third most common source of information. The least source of information was the radio, with a mean score of 1.32 .

In order to identify the effect of risk perception on behavior response, the linear regression analysis was performed. Figure $6(\mathrm{~A})$ shows the findings of the regression analysis between the overall risk perception and overall protective behavior and then the risk perception items individually (risk of getting infection, risk of getting a serious illness, and risk of dying) with the overall protective behavior. There is a statistically significant weak positive correlation between the overall risk perception and overall protective behavior at $P<0.001$, with a regression coefficient of 0.079 and a correlation coefficient of 0.206 .

Regarding the regression analysis between risk perception of getting infection from COVID-19 and overall protective behavior, the regression coefficient was $0.063(r=0.190, P<0.001)$. This may suggest that an increase in one unit in risk perception is associated with an increase of 0.063 units in overall protective behavior. Similar findings can be noticed concerning risk of getting serious illness (beta $=0.070, r=0.197$, $P<0.001$ ); and the risk of death (beta $=0.058, r=0.169, P<0.001$ ).

Figure 6 (B) illustrates the regression analysis between the overall risk perception with the four main recommended protective behaviors of handwashing, social distancing, respiratory hygiene, and avoid touching the face. The analysis indicates that there is a statistically significant weak positive correlation between the overall risk perception with the main protective behaviors as $P<0.001$, and the coefficient regression was $0.080(r=0.189)$. This suggests that an increase of one unit in overall risk perception is associated with an increase of 0.08 units in the main protective behaviors. In addition, there was a statistically significant positive correlation $(P<0.001)$ between all the individual items of risk perception with the main protective behaviors: risk of getting infection (beta $=0.066, r=0.179$ ), risk of getting serious illness (beta $=0.070, r=0.176$ ) and lastly risk of dying (beta $=0.058, r=0.154)$.

\section{Discussion}

The current study provides timely assessment and early evidence to understand the risk perception and the behavioral response of the university academics and students towards the outbreak of the COVID-19 in Iraqi Kurdistan Region. Understanding how psychological factors influence one's behavior in pandemics like COVID-19 is crucial in facilitating disease reduction strategies. Our analysis indicates that although the majority of respondents had the highest perceived threat level towards COVID-19 compared 
to other medical threats. They typically underestimate their personal risk perception of getting infection, serious illness, and death. In contrast, a study conducted in Vietnam by Huynh in 2020 reported that the average perceived risk was considerably high among a Vietnamese sample [12]. It was also found that the geographical location has an impact on risk perception of COVID-19, as Vietnam is one of China's neighboring countries where the outbreak first emerged.

One of the important findings in our study is that although respondents perceived their risk of getting infection, risk of serious illness, and death from COVID-19 as highly unlikely, they were engaged in protection behaviors. This is in agreement with a study conducted in China by Wang et al. as they reported that their respondents adopted precautionary measures such as handwashing, respiratory hygiene in the outbreak of COVID-19 [13]. Respondents' adopting protective measures in the current study might be due to the fact that our sample was well educated. Zhan et al. reported that better protection behavior was associated with people with higher education [14]. In addition, in a review conducted by Bish \& Michie to identify the essential demographic and attitudinal of different types of protective behavior, identified that more education is associated with a higher chance of applying protective behaviors [15]. Interestingly, our analysis indicates that there was a weak positive correlation between the overall risk perception and overall engagement in protective behaviors. Studies have shown that the higher the perceived risk, the more people apply protective measures $[5,15]$.

Although current respondents engage in protection behaviors quite noticeably, they still had a low mean score for some important protective behaviors such as avoiding touching face, nose, and mouth. It is well noted in the literature that behavior change is quite difficult and challenging. The findings of Bouton suggest that changing a behavior can be an intrinsically unsteady and unstable process [16].

In the dearth of other relevant studies to compare the current study's findings, it is logical to compare our findings with similar contagious outbreaks like influenza A (HIN1). We found that respondents had a higher perceived threat level towards the COVID-19 compared to other medical threats, and this was the case in the influenza A (HIN1) pandemic, as reported by Jones and Salathe [8]. The majority of respondents in our sample perceived their risk of infection as highly unlikely, and at the same time, they perceived that they have the ability to avoid infection; comparable findings documented by Jones and Salathe [8].

Most of the health authorities worldwide recommend 'social distancing' as an effective method in reducing disease transmission, especially when dealing with pandemics as COVID-19 since people might be infectious but at the same time asymptomatic [17]. This is quite important in places where community transmission has occurred [18].

As mentioned earlier, in the early stage of the COVID-19 pandemic, the KRG adopted several measures to contain and mitigate the disease. As community spread of the infection disease occurs, the governmental measures cannot guarantee the control of the COVID-19 alone. What is more important in such contagious outbreaks is the adoption of protective behaviors by individuals in the community $[19,20]$. Since community transmission is believed to have occurred in the KRG [9], restricted measures were taken 
by the KRG in order to contain the spread of the disease. For instance, curfew in all the governorates of the KRG put in place, all public transportation types have been suspended, and major movement restriction of everyone (quarantine) except for minimal encounter, and that is for necessity supply. This has mirrored in our finding, as the majority of respondents had zero contacts outside their households. In contrast to our findings, Jones and Salathe reported that participants had a number of contacts during the early days of the influenza A (HIN1) outbreak in 2009 [8]. The reason behind this disagreement is that the current situation is quite different from the COVID-19 pandemic as not only the KRG emplaced restriction on wide-community movement and recommendations from health officials reinforce the importance of staying at home, the majority of countries apply similar measures.

However, in a review conducted by Brooks and her colleagues, it was documented that quarantine had a negative psychological impact, such as confusion and anger. The authors recommend that officials have to take measures to keep the quarantines period as short as possible and disseminate clear information and justification regarding the quarantine or curfew regulations [21]. This has to be considered by policymakers in Kurdistan region.

The sources of information about COVID-19 varied across the respondents. Our findings revealed that university academics and students used the website most frequently, among other sources. This suggests that academics and students rely highly on different online sources in order to obtain updates regarding the COVID-19 outbreak. This result is in accordance with the findings obtained by Wang and colleagues as they stated that $93.5 \%$ of their respondents obtained health information regarding COVID19 from the internet [13]. However, it is important to state that the second most frequently used source of information was social media, and this is in considerable concern, due to the fact that the information is quickly circulating on social media which might lead to faster spreading of unreliable information, and this may, in turn, mislead one's responses towards the outbreak.

One of the advantages of this online survey is the ability to obtain a timely response in a situation when other means of data collection might be difficult due to health and safety reasons. Nevertheless, the present study is subject to some limitations. The total number of respondents is considerably small compared to the target population (university teaching staff and students) in the KRG. This might be considered one of the limitations of the current study. However, it is important to note that the notion and practicality of online surveys in the region are quite new as people may not be familiar with these kinds of surveys. For that reason for the current study, the number of respondents could be considered reasonable. In addition, the mean age of our sample is relatively young. Nevertheless, our sample reflects the target population, as the majority of them are students. Additionally, the findings of the current study are limited to a sample of university academics and students in KRG. Therefore, it cannot be generalized to the general public. However, the authors' intention is to conduct similar surveys targeting the general public in the near future.

\section{Conclusion}


The perceived risk of getting infection with COVID-19 is relatively low. The respondents follow the protective behavior measure in a good manner. However, the frequency of undertaking some important protective behaviors is relatively low, such as touching face, respiratory hygiene, and the use of disinfectants. The risk perception of COVID-19 has a weakly positive impact on following protective behavior. Changing behavior remains a challenge even for the well educated and well aware people, which requires further intensification of the efforts and finding more effective ways of awareness and behavior change.

\section{Abbreviations}

COVID-19

Coronavirus disease

\section{Declarations}

\section{Ethics approval and consent to participate}

This study was approved by the Research Ethics Committee of Hawler Medical University. Consent was obtained for each participant before completing the online survey. All participants were informed about the voluntary nature of participation and the anonymity and confidentiality of information.

\section{Consent for publication}

Not applicable.

\section{Availability of the data and materials}

The datasets used for the current study will be available from the corresponding author on a reasonable request.

\section{Funding}

Not applicable.

\section{Author's contributions}

SAS participated in conceiving and designing the study, contributed to drafting the manuscript and read and approved the final manuscript. KMA participated in conceiving and designing the study, contributed to drafting the manuscript and read and approved the final manuscript. KIM participated in designing the study, contributed to drafting the manuscript, and read and approved the final manuscript. NPS participated in conceiving and designing the study, carried out data analysis, edited, and finalized the manuscript.

\section{Competing interests}


The authors declare that they have no competing interests.

\section{References}

1. World Health Organization. Coronavirus. Overview. . Accessed 23 Mar 2020.

2. World Health Organization. Coronavirus disease 2019 (COVID-19) situation report-44. 4. Mar 2020. 9d_2 3. Accessed 25 Mar 2020.

3. World Health Organization. Coronavirus disease (COVID-19) advice for the public. Basic protective measures against the new coronavirus. . Accessed 25 Mar 2020.

4. Halloran ME, Ferguson NM, Eubank S, Longini IM, Cummings DA, Lewis B, et al. Modeling targeted layered containment of an influenza pandemic in the United States. Proceedings of the National Academy of Sciences. 2008;105(12):4639-44.

5. Rubin GJ, Amlôt R, Page L, Wessely S. Public perceptions, anxiety, and behaviour change in relation to the swine flu outbreak: cross sectional telephone survey. BMJ. 2009;339:b2651.

6. Leung GM, Lam TH, Ho LM, Ho SY, Chan BH, Wong IO, et al. The impact of community psychological responses on outbreak control for severe acute respiratory syndrome in Hong Kong. J Epidemiol Community Health. 2003;57(11):857-63.

7. De Zwart O, Veldhuijzen IK, Elam G, Aro AR, Abraham T, Bishop GD, Richardus JH, Brug J. Avian influenza risk perception, Europe and Asia. Emerg Infect Dis. 2007;13(2):290.

8. Jones $\mathrm{JH}$, Salathe M. Early assessment of anxiety and behavioral response to novel swin-origin influenza A (H1N1). PLoS ONE. 2009;4(12):e8032.

9. Kurdistan Regional Government. Situation update. Coronavirus (COVID-19). . Accessed 27 Mar 2020.

10. Cowling BJ, Ng DM, Ip DK, Liao Q, Lam WW, Wu JT, et al. Community psychological and behavioral responses through the first wave of the 2009 influenza A (H1N1) pandemic in Hong Kong. $J$ Infect Dis. 2010;202(6):867-76.

11. Goodwin R, Haque S, Neto F, Myers LB. Initial psychological responses to Influenza A, H1N1 ("Swine flu"). BMC Infect Dis. 2009;9:166.

12. Huynh TL. The COVID-19 risk perception: A survey on socioeconomics and media attention. Economics Bulletin. 2020;40(1):758-64.

13. Wang C, Pan R, Wan X, Tan Y, Xu L, Ho CS, et al. Immediate psychological responses and associated factors during the initial stage of the 2019 coronavirus disease (COVID-19) epidemic among the general population in china. Int J Environ Res Public Health. 2020;17(5):1729.

14. Zhan S, Yang YY, Fu C. Public's early response to the novel coronavirus-infected pneumonia. Emerg Microbes Infect. 2020;9(1):534.

15. Bish A, Michie S. Demographic and attitudinal determinants of protective behaviours during a pandemic: a review. Br J Health Psychol. 2010;15(4):797-824.

16. Bouton ME. Why behavior change is difficult to sustain. Prev Med. 2014 Nov;1:68:29-36. 
17. Mahase E. Covid-19: UK starts social distancing after new model points to 260000 potential deaths. BMJ. 2020;368:m1089.

18. Wilder-Smith A, Freedman DO. Isolation, quarantine, social distancing and community containment: pivotal role for old-style public health measures in the novel coronavirus (2019-nCoV) outbreak. J Travel Med. 2020;27(2):taaa020.

19. Anderson RM, Heesterbeek H, Klinkenberg D, Hollingsworth TD. How will country-based mitigation measures influence the course of the COVID-19 epidemic? Lancet. 2020;395(10228):931-4.

20. Lau JT, Griffiths S, Choi KC, Lin C. Prevalence of preventive behaviors and associated factors during early phase of the H1N1 influenza epidemic. Am J Infect Control. 2010;38(5):374-80.

21. Brooks SK, Webster RK, Smith LE, Woodland L, Wessely S, Greenberg N, et al. The psychological impact of quarantine and how to reduce it: rapid review of the evidence. Lancet. 2020;395(10227):912-20.

\section{Figures}

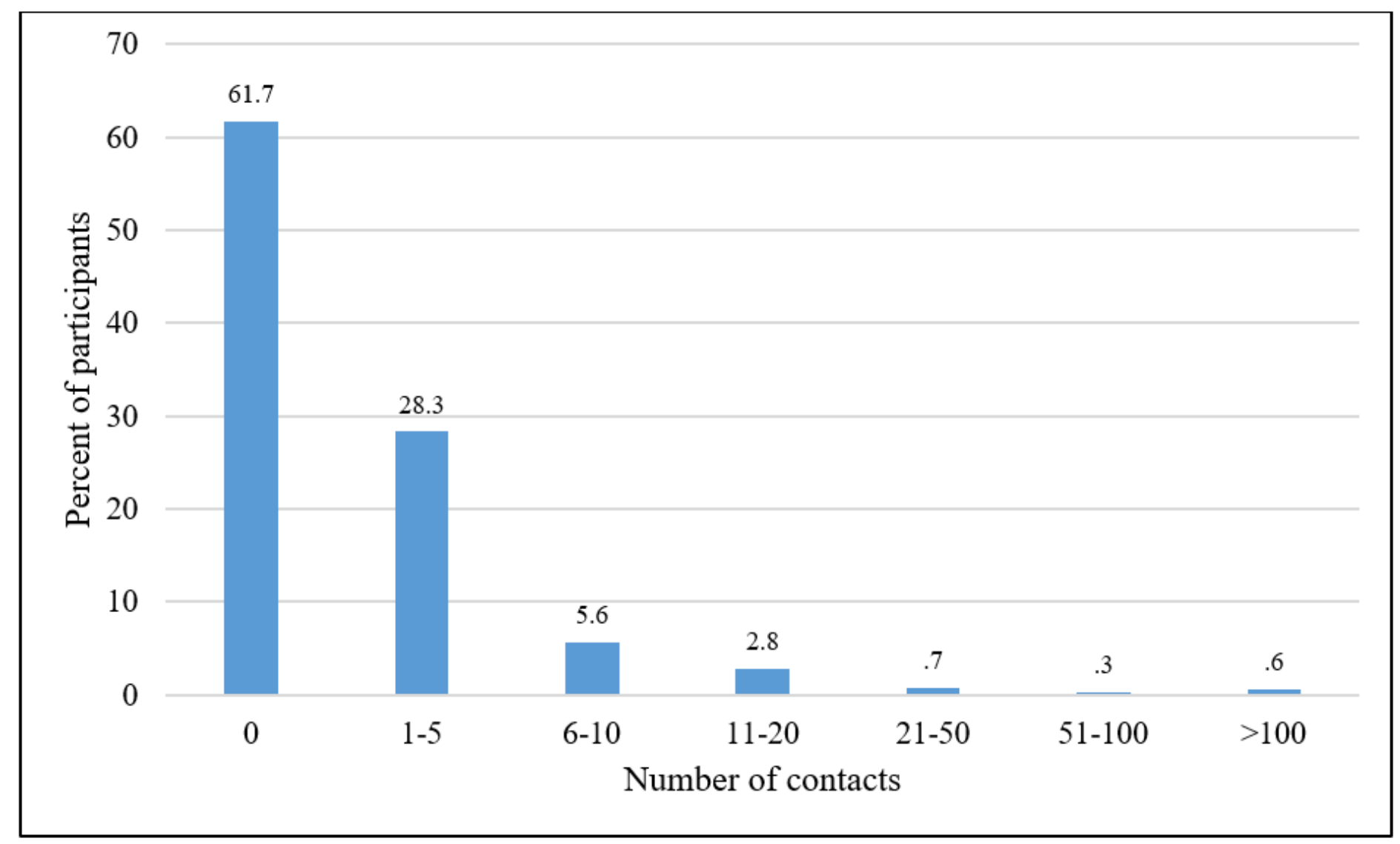

\section{Figure 1}

The mean score and $95 \%$ confidence interval of the perceived threat level of COVID-19 in comparison with other important diseases. $0=$ very low threat, $5=$ very high threat 


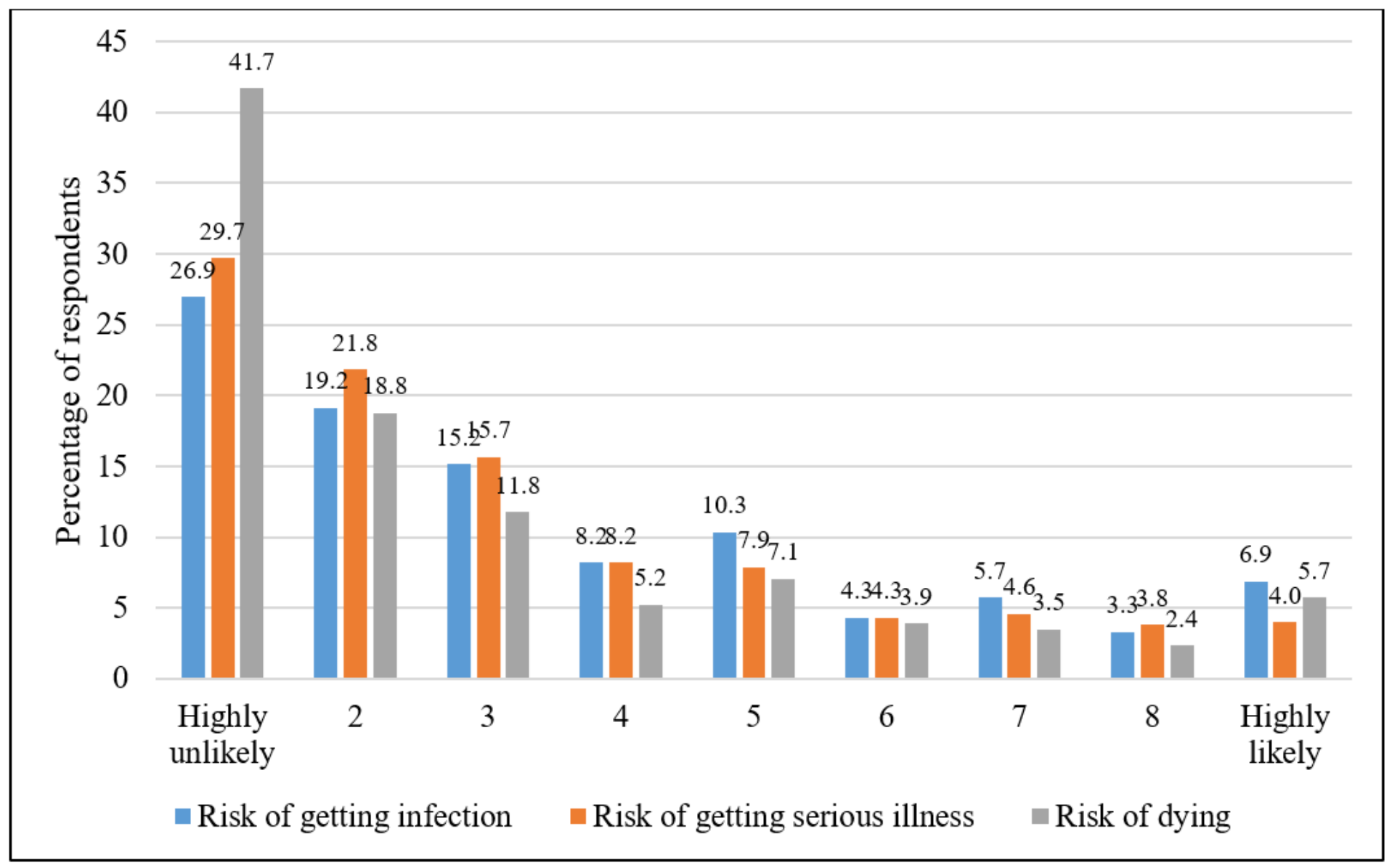

Figure 2

Respondents' risk perception of getting infection, serious illness and death from COVID-19. 


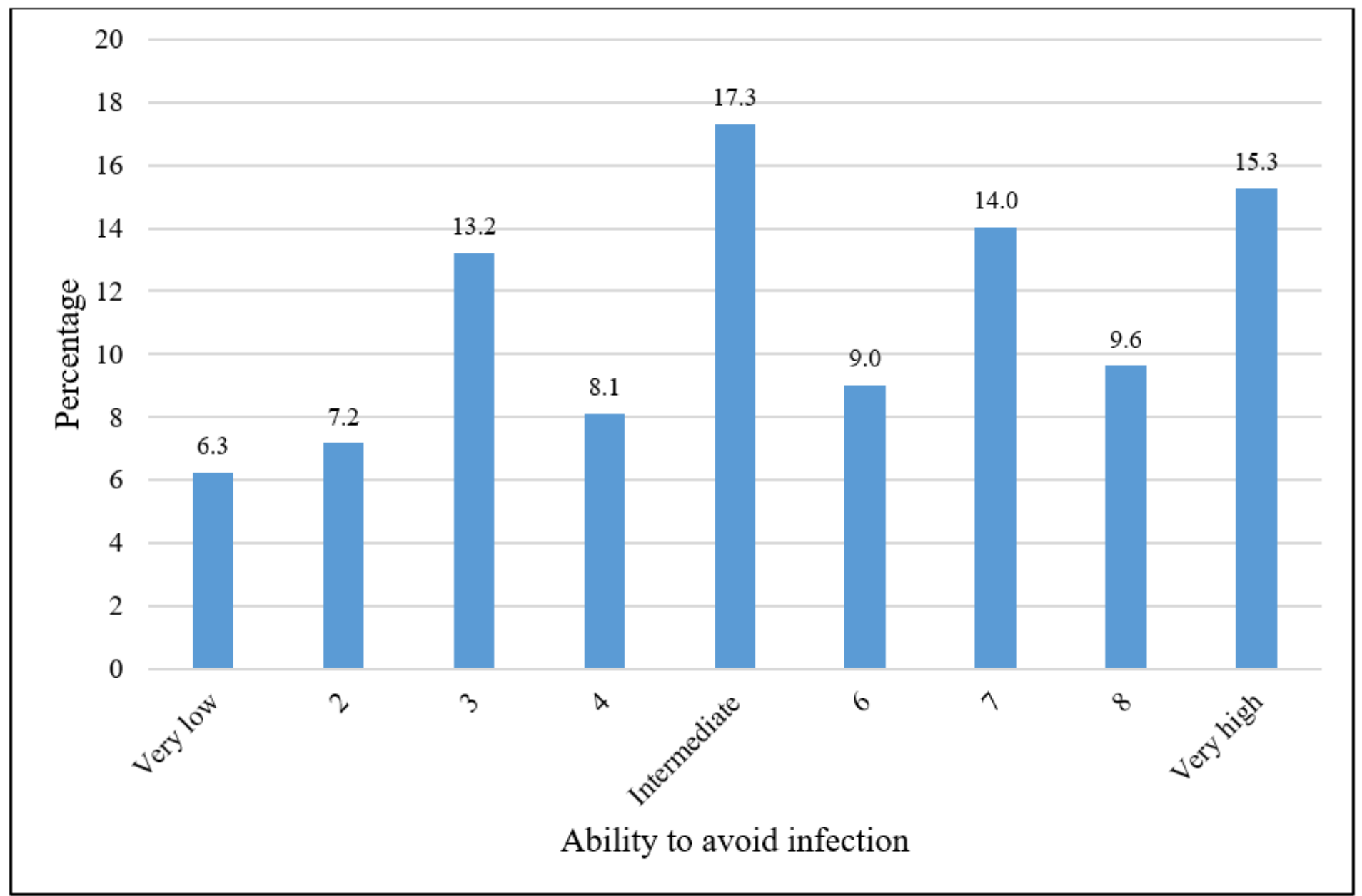

Figure 3

Respondents' perceived ability to avoid infection with COVID-19. 


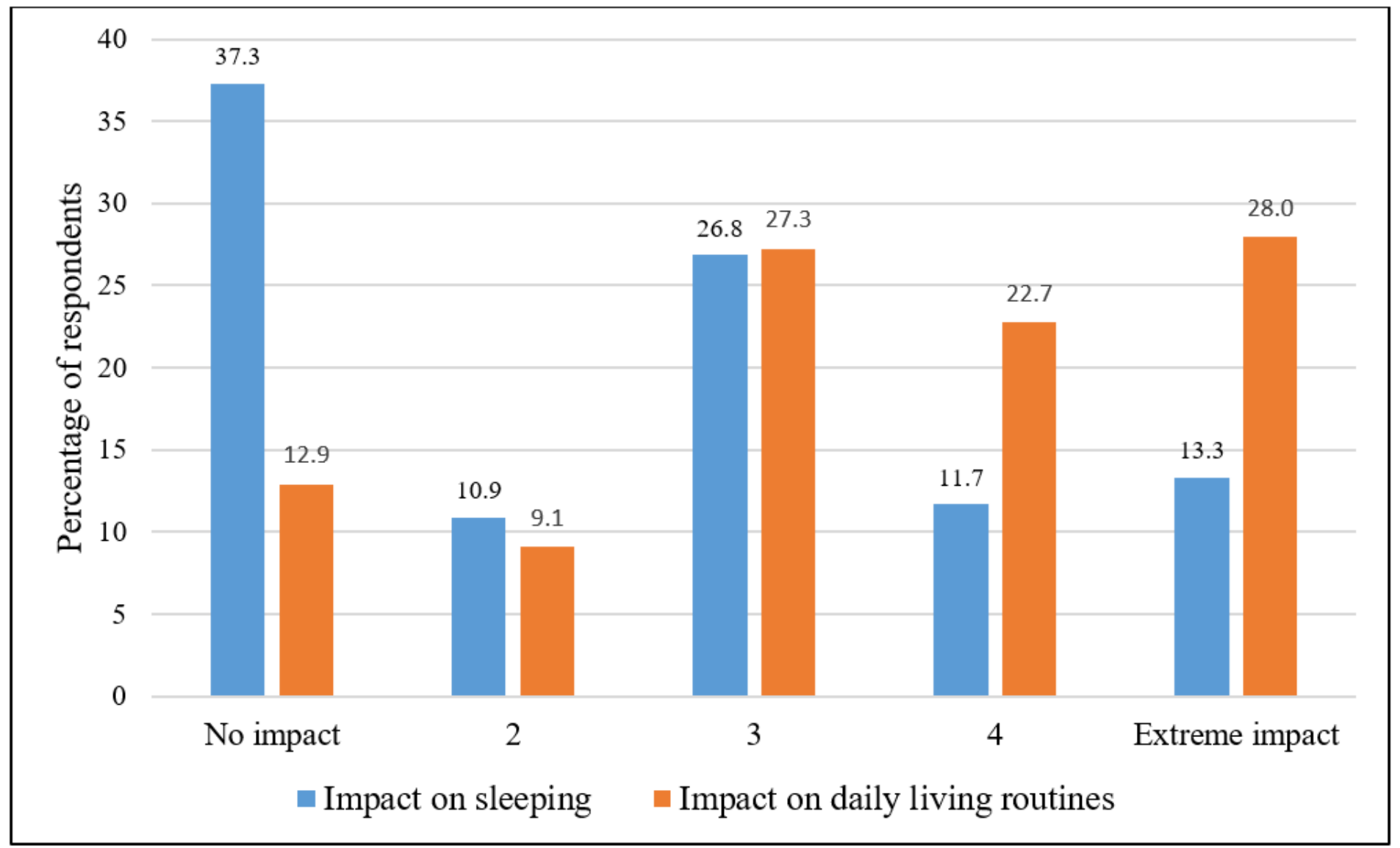

Figure 4

Impact of COVID-19 on sleeping and daily living routines of the respondents. 


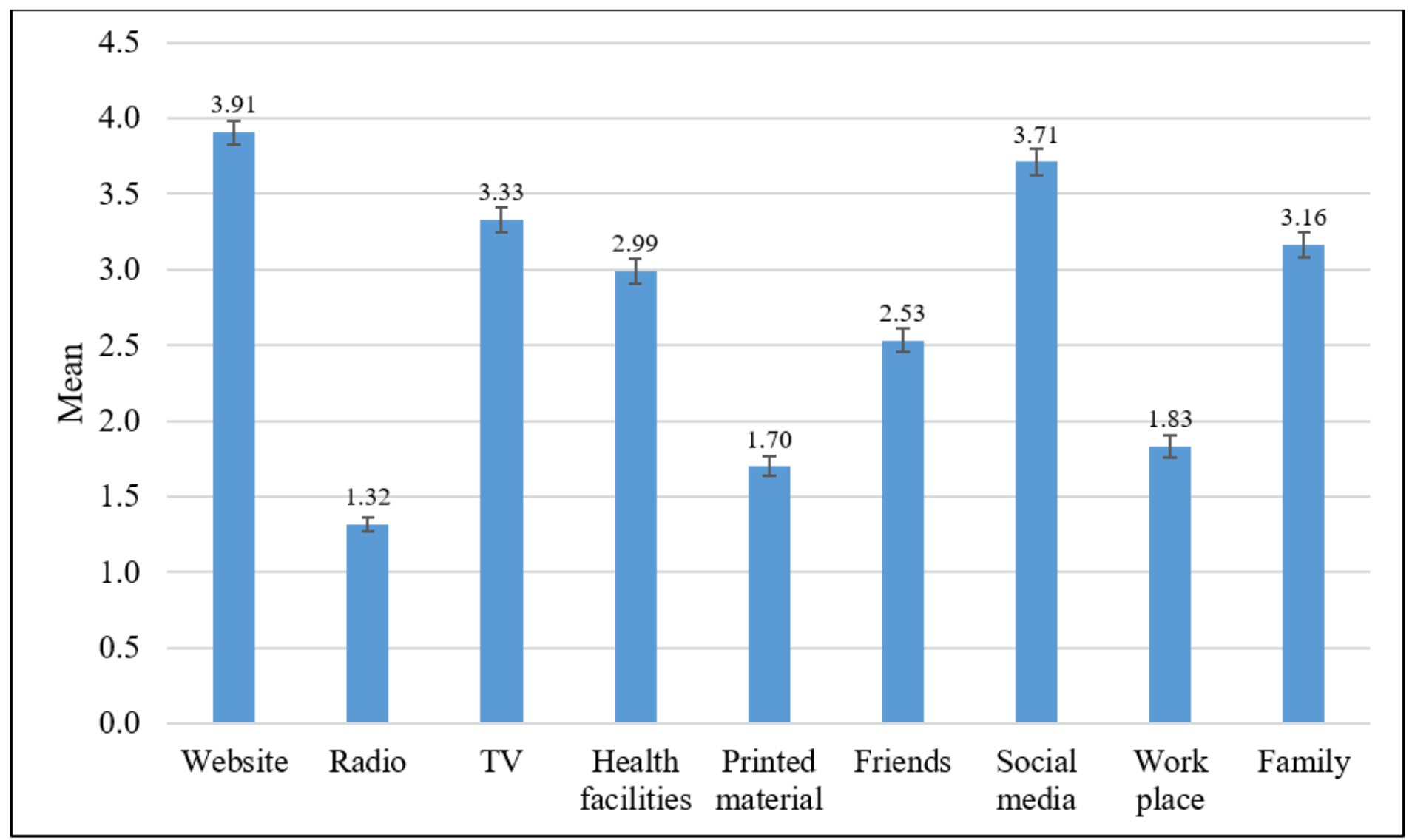

Figure 5

The mean score and $95 \%$ confidence interval of the sourced of information about COVID-19 0=Never, $5=$ Very frequently 


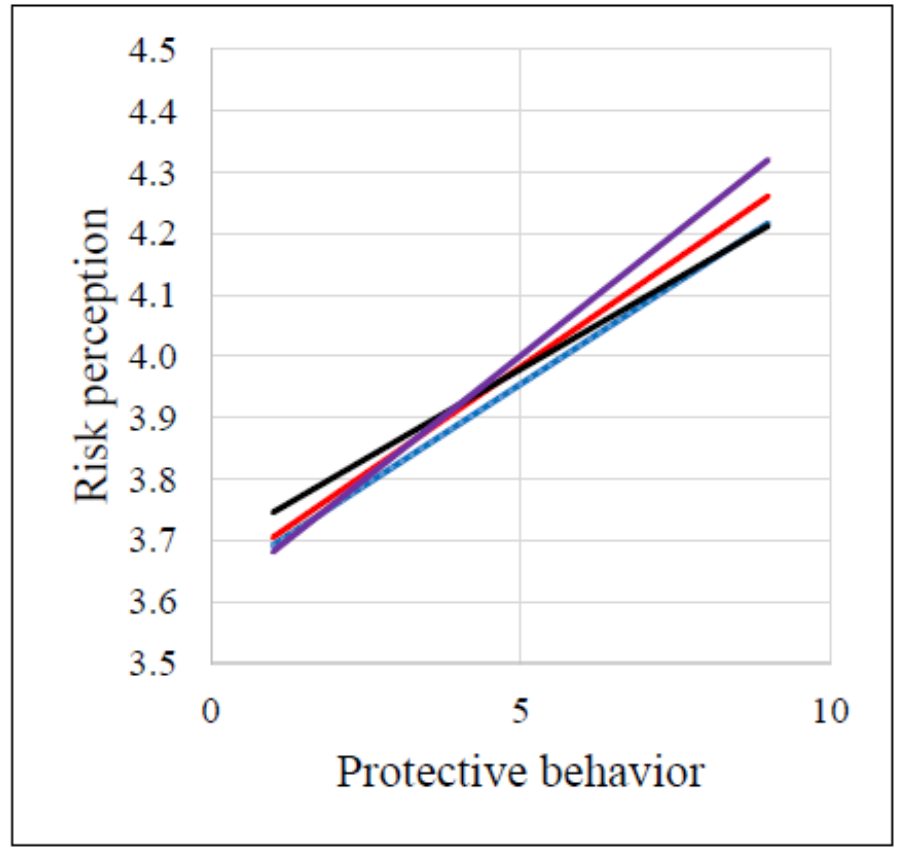

- Infection

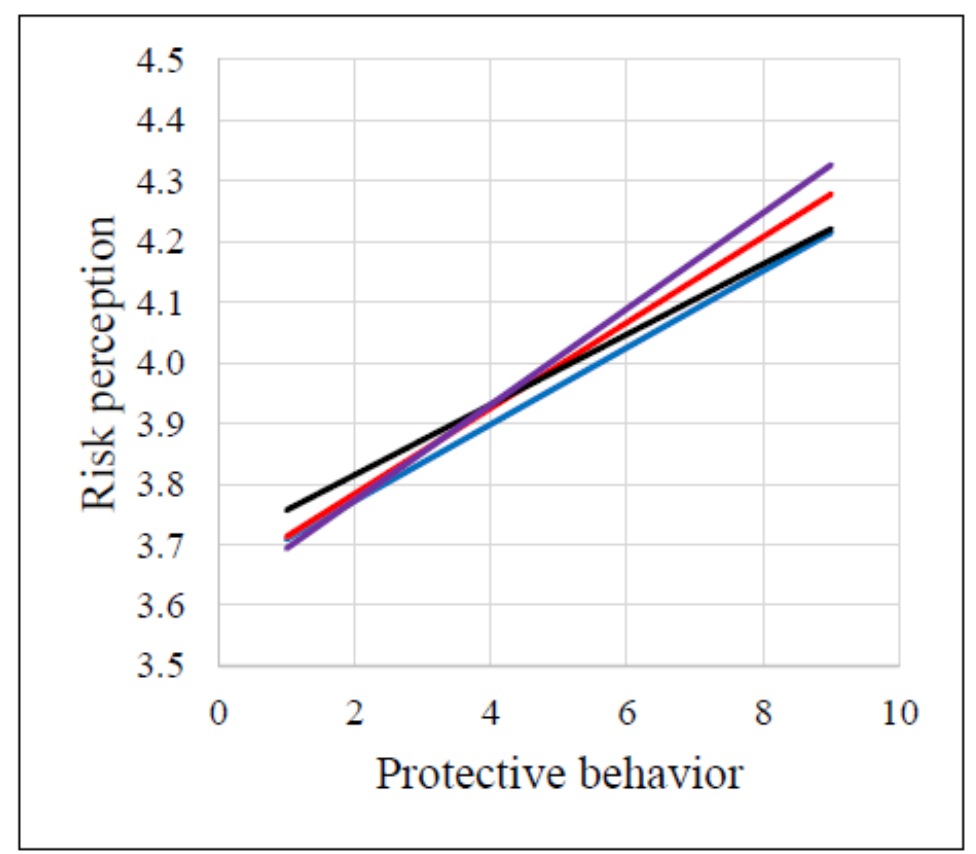

Death

\section{Overall risk}

\section{Figure 6}

Linear regression between COVID-19 risk perception and protective behavior response among the respondents. (A) Risk perception vs. overall protective behaviors together. (B) Risk perception vs. main protective behaviors (handwashing, social distancing, respiratory hygiene, avoid touching face) 